\title{
CrystEngComm
}

\section{Lutidine adducts of urea: molecular mechanisms for twinning effects on cooling $\dagger$}

Cite this: CrystEngComm, 2014, 16 5695

Received 18th March 2014, Accepted 4th May 2014

DOI: $10.1039 / \mathrm{c} 4 \mathrm{ce} 00560 \mathrm{k}$

www.rsc.org/crystengcomm

\author{
Christina Taouss and Peter G. Jones*
}

\section{Introduction}

We are interested in simple solvates of urea and thiourea, which we define as their adducts with compounds that are liquids at room temperature, and have recently reported the structures of urea: morpholine (1:1), urea:1,4-dioxane (1:1), thiourea: morpholine $(4: 3)$ and thiourea:1,4-dioxane $(4: 1){ }^{1}$ this article may also be consulted for a brief summary of the relevant literature. The 1:1 adduct of urea with 2,6-lutidine, henceforth adduct 1 , was determined in space group $C 2 / c$ from photographic data in projection, ${ }^{2}$ and it seemed worthwhile to repeat this structure using more modern methods, and to investigate the $2: 1$ adduct 2 whose existence, but not structure, was reported in the same paper. A related 1:1

Institut für Anorganische und Analytische Chemie, Technische Universität Braunschweig, Postfach 3329, D-38023 Braunschweig, Germany. E-mail: p.jones@tu-bs.de;

Fax: +49 531 5387; Tel: +495315382

$\dagger$ CCDC 990312 (1m), 990308 (1t), 990309 (2), 990311 (3o), 990310 (3m) contain the supplementary crystallographic data for this paper. For crystallographic data in CIF or other electronic format see DOI: 10.1039/ c4ce00560k adduct is that of urea with 2-picoline. ${ }^{3}$ We also wished to extend the series of urea adducts with liquid pyridine derivatives, and the obvious first choice was 3,5-lutidine. Here we report the structures of urea:2,6-lutidine $(2: 1) 2$, two polymorphs of urea:2,6-lutidine $(1: 1) 1$, and two polymorphs of urea :3,5-lutidine $(2: 1) 3$. In each case the polymorph that is formed on cooling is twinned.

Twinning is a crystallographic topic that is often regarded as "difficult" and thus the preserve of a handful of experts, ${ }^{4}$ and some of the more mathematical treatments are indeed impenetrable to the everyday chemist. However, diffractometer software and structure refinement programs have now been improved to the extent that twinning has become a more accessible phenomenon, and the practising crystallographer can often acquire all the knowledge necessary for the successful analysis of most twinned structures. Less well understood is the question as to how twins are formed; for molecular structures, we are aware of few examinations ${ }^{5}$ of the molecular mechanism of twinning (although it is difficult to perform an exhaustive literature search and we may have missed other examples). Here, the relationships between the polymorph 
pairs of $\mathbf{1}$ and $\mathbf{3}$ are analysed in detail, which provides a basis for explaining the molecular mechanisms of the twinning phenomena.

\section{Experimental}

\section{Crystal growth}

Adduct 1 was obtained as single crystals by overlayering a solution of urea in methanol with 2,6-lutidine. Crystals of the $2: 1$ adduct 2 formed when a solution of urea in methanol and 2,6-lutidine was overlayered with diethyl ether. For 3,5-lutidine, we were only able to crystallize the $2: 1$ adduct 3 , by allowing a solution of urea in 3,5-lutidine and methanol to stand for several days. All the adducts lose lutidine under ambient conditions.

\section{X-ray crystallography}

Unexpectedly, initial crystallographic investigations of the 1:1 adduct 1 of urea with 2,6-lutidine did not reveal the same cell as that found previously; ${ }^{2}$ at $100 \mathrm{~K}$ the diffraction patterns invariably showed split reflections, and could be indexed successfully as (non-merohedrally) twinned triclinic (1t) rather than monoclinic (1m). Despite the twinning, the structure was successfully determined. The structure of the $2: 1$ adduct 2 was registered in a straightforward manner. Crystals of the $2: 1$ adduct with 3,5-lutidine 3 were orthorhombic (3o) and showed a marked tendency to shatter at low temperatures (sometimes immediately, sometimes after a few hours); the structure determination of $\mathbf{3 0}$ was finally accomplished at $173 \mathrm{~K}$. This led us to suppose that adduct 1 might behave in a similar fashion, and thus that the structure $1 \mathrm{~m}$ might be successfully redetermined at somewhat higher temperatures; this was indeed done at $200 \mathrm{~K}$. Finally, the structure of a monoclinic form of 3 (3m) was determined by cooling the orthorhombic form slowly to $100 \mathrm{~K}$; many crystals shattered but one, although twinned, was successfully measured.

Details of intensity measurements and refinements are given in Table 1. Crystals were mounted in inert oil on glass fibres. Data were measured with an Oxford Diffraction Xcalibur E diffractometer using monochromated Mo K $\alpha$ radiation or with an Oxford Diffraction Nova A diffractometer using mirror-focussed $\mathrm{Cu} \mathrm{K} \alpha$ radiation; multi-scan absorption corrections were performed in some cases. ${ }^{6}$ The structures were solved with direct methods using SHELXS-97, and structure refinement was performed with full-matrix leastsquares on $F^{2}$ using SHELXL-97 ${ }^{7 a}$ or SHELXL-2012. ${ }^{7 b} \mathrm{NH}$ hydrogens were refined freely and aromatic hydrogens using a riding model. Well-defined methyl groups were included as idealised rigid groups allowed to rotate but not tip, but the hydrogen sites were in some cases indistinct and were approximated where necessary as a hexagon of half-occupied hydrogen sites corresponding to rotational disorder; in other cases the methyl hydrogens were disordered over special positions (details are given in the deposited CIF files). Molecular graphics were prepared with XP. ${ }^{8}$

Table 1 Experimental details of the structure determinations

\begin{tabular}{|c|c|c|c|c|c|}
\hline Solvate & $\begin{array}{l}\text { Urea : 2,6-lutidine } \\
(1: 1), \mathbf{1 m}\end{array}$ & $\begin{array}{l}\text { Urea : } 2,6 \text {-lutidine } \\
(1: 1), 1 \mathrm{t}\end{array}$ & $\begin{array}{l}\text { Urea : } 2,6 \text {-lutidine } \\
(2: 1), 2\end{array}$ & $\begin{array}{l}\text { Urea }: 3,5 \text {-lutidine } \\
(2: 1), 30\end{array}$ & $\begin{array}{l}\text { Urea : } 3,5 \text {-lutidine } \\
(2: 1), 3 \mathrm{~m}\end{array}$ \\
\hline Chemical formula & $\mathrm{C}_{8} \mathrm{H}_{13} \mathrm{~N}_{3} \mathrm{O}$ & $\mathrm{C}_{8} \mathrm{H}_{13} \mathrm{~N}_{3} \mathrm{O}$ & $\mathrm{C}_{9} \mathrm{H}_{17} \mathrm{~N}_{5} \mathrm{O}_{2}$ & $\mathrm{C}_{9} \mathrm{H}_{17} \mathrm{~N}_{5} \mathrm{O}_{2}$ & $\mathrm{C}_{9} \mathrm{H}_{17} \mathrm{~N}_{5} \mathrm{O}_{2}$ \\
\hline$M_{\mathrm{r}}$ & 167.21 & 167.21 & 227.28 & 227.28 & 227.28 \\
\hline $\begin{array}{l}\text { Crystal system, } \\
\text { space group }\end{array}$ & Monoclinic, $C 2 / c$ & Triclinic, $P \overline{1}$ & Orthorhombic, Pnma & Orthorhombic, $A b m 2$ & Monoclinic, $C c$ \\
\hline Temperature (K) & 200 & 100 & 100 & 173 & 100 \\
\hline$a(\AA)$ & $11.426(2)$ & $7.4126(6)$ & $8.0772(3)$ & $21.7368(15)$ & $8.5829(4)$ \\
\hline$b(\AA)$ & 11.1168(9) & $7.6720(6)$ & $7.2986(3)$ & $7.2102(6)$ & $21.4843(8)$ \\
\hline$c(\AA)$ & $7.4318(8)$ & $8.1731(6)$ & $20.4169(7)$ & $15.5904(15)$ & $7.2050(4)$ \\
\hline$\alpha\left({ }^{\circ}\right)$ & 90 & $88.391(6)$ & 90 & 90 & 90 \\
\hline$\beta\left({ }^{\circ}\right)$ & $101.235(15)$ & $83.564(6)$ & 90 & 90 & $114.405(6)$ \\
\hline$\gamma\left({ }^{\circ}\right)$ & 90 & $80.059(6)$ & 90 & 90 & 90 \\
\hline$V\left(\AA^{3}\right)$ & 925.9 & 454.92 & 1203.64 & 2443.4 & 1209.87 \\
\hline$d_{\text {calc }}\left(\mathrm{g} \mathrm{cm}^{3}\right)$ & 1.200 & 1.221 & 1.254 & 1.236 & 1.248 \\
\hline$Z$ & 4 & 2 & 4 & 8 & 4 \\
\hline Radiation, & Mo K $\alpha$, & $\mathrm{Cu} \mathrm{K} \alpha$ & Mo K $\alpha$, & Mo K $\alpha$, & $\mathrm{Cu} \mathbf{K} \alpha$ \\
\hline wavelength & $\lambda=0.71073 \AA$ & $\lambda=1.54184 \AA$ & $\lambda=0.71073 \AA$ & $\lambda=0.71073 \AA$ & $\lambda=1.54184 \AA$ \\
\hline$F(000)$ & 360 & 180 & 488 & 976 & 488 \\
\hline$\mu\left(\mathrm{mm}^{-1}\right)$ & 0.08 & 0.7 & 0.09 & 0.09 & 0.8 \\
\hline Crystal size (mm) & $0.25 \times 0.25 \times 0.08$ & $0.20 \times 0.15 \times 0.03$ & $0.35 \times 0.15 \times 0.15$ & $0.3 \times 0.13 \times 0.02$ & $0.2 \times 0.16 \times 0.08$ \\
\hline Transmissions & No abs. corr. & $0.80-1.00$ & No abs. corr. & $0.93-1.00$ & $0.87-1.00$ \\
\hline $2 \theta_{\max }\left({ }^{\circ}\right)$ & 50 & 152 & 58.7 & 52.7 & 153 \\
\hline $\begin{array}{l}\text { No. of measured and } \\
\text { independent reflections }\end{array}$ & 5818,819 & 3650 & 38287,1710 & 21459,1409 & 27700,2403 \\
\hline Completeness & $100 \%$ to $2 \theta_{\max }$ & $99.9 \%$ to $2 \theta 150^{\circ}$ & $99.8 \%$ to $2 \theta 57^{\circ}$ & $99.9 \%$ to $2 \theta_{\max }$ & $99.9 \%$ to $2 \theta 150^{\circ}$ \\
\hline$R_{\text {int }}$ & 0.033 & - & 0.029 & 0.060 & 0.052 \\
\hline $\mathrm{w} R\left(F^{2}\right)$ all refl., $R_{1}[F>4 \sigma(F)], S\left(F^{2}\right)$ & $0.134,0.053,1.04$ & $0.107,0.039,1.05$ & $0.110,0.041,1.06$ & $0.089,0.040,1.04$ & $0.132,0.047,1.08$ \\
\hline No. of parameters/restraints & $66 / 0$ & $128 / 0$ & $108 / 0$ & $217 / 29$ & $173 / 36$ \\
\hline$\Delta \rho_{\max , \min }\left(\mathrm{e} \AA^{-3}\right)$ & $0.27,-0.24$ & $0.18,-0.20$ & $0.45,-0.33$ & $0.13,-0.18$ & $0.36,-0.25$ \\
\hline
\end{tabular}


The atom numbering employed here does not always conform to the standard urea numbering, with $\mathrm{N} 1-\mathrm{C} 2(=\mathrm{O})-\mathrm{N} 3$, because of the frequent occurrence of crystallographic symmetry within the urea molecule. The urea hydrogens are numbered as H0x, whereby $x$ is odd if the hydrogen is trans to $\mathrm{O}=\mathrm{C}$ across the $\mathrm{N}-\mathrm{C}$ bond and even if it is cis.

Special features. Structure 1t was interpreted as a nonmerohedral twin generated by $180^{\circ}$ rotation about the vector $\left(\boldsymbol{b}^{*}-\boldsymbol{c}^{*}\right)$ and was refined using the HKLF5 method; ${ }^{7 a, 9}$ the relative volume of the smaller component refined to $0.495(1)$. Because equivalent reflections are merged and reflections from both twin components are present, the number of reflections should be interpreted with caution. Structure $3 \mathbf{m}$ was also interpreted as a twin, generated by $180^{\circ}$ degree rotation about $\boldsymbol{a}^{*}$. The twin matrix is to a good approximation (101/0-10/00-1), which because of its whole numbers leads to almost exact superposition of reflections from both twin components (there are no obviously split reflections); however, there is no effective overlap when one of the potentially overlapping reflection is absent because of lattice centring (e.g. reflections of parity group uuu from the first component will "overlap" with guu from the second component, but the latter are lattice absences). This is sometimes termed "reticular pseudomerohedry"10 and can be allowed for in the program SHELXL-2012 ${ }^{7 b}$ (but not in earlier versions of the program) by simply giving the twin matrix; the relative volume of the smaller component refined to $0.220(7)$. Because of the poorer data/parameter ratio of $3 \mathrm{~m}(\mathrm{Cu}$ radiation, noncentrosymmetric structure), its $\mathrm{N}-\mathrm{H}$ and amino $\mathrm{H} \cdots \mathrm{H}$ distances were restrained to be equal, and the $\mathrm{NH}$ hydrogens were refined using a common displacement factor. For the non-centrosymmetric structure 3o, amino $\mathrm{N} \cdots \mathrm{H}$ distances were restrained to be equal. The anomalous dispersion of 30 with Mo $\mathrm{K} \alpha$ radiation was negligible; the Friedel pairs were merged and the Flack parameter is thus meaningless. For $3 \mathrm{~m}$, the anomalous scattering was just significant, and the absolute structure parameter was determined as $0.06(14) .{ }^{11}$ Attempts to allow for inversion twinning gave two additional BASF parameters (the relative volumes of the additional twinning components) not significantly different from zero and were therefore abandoned.

\section{Results and discussion}

Crystal structure of urea : 2,6-lutidine (1:1), higher temperature form (1m)

The redetermination of the structure of solvate $\mathbf{1 m}$, measured at $-73^{\circ} \mathrm{C}$, confirms the qualitative features reported previously. $^{2}$ It crystallizes in $C 2 / c$ with $Z=4$. The formula unit is shown in Fig. 1, The atoms C1, O1, N11 and C14 lie on the twofold axis at $x=1 / 2, z=3 / 4$, so that both residues display crystallographic twofold symmetry. There is clearly considerable libration of the lutidine ring, and its dimensions should be interpreted with caution. Attempts to refine alternative models (in $C c$; in $P \overline{1}$ as a pseudomerohedral twin; or disordered in $C 2 / c$ ) led to no significant improvement.

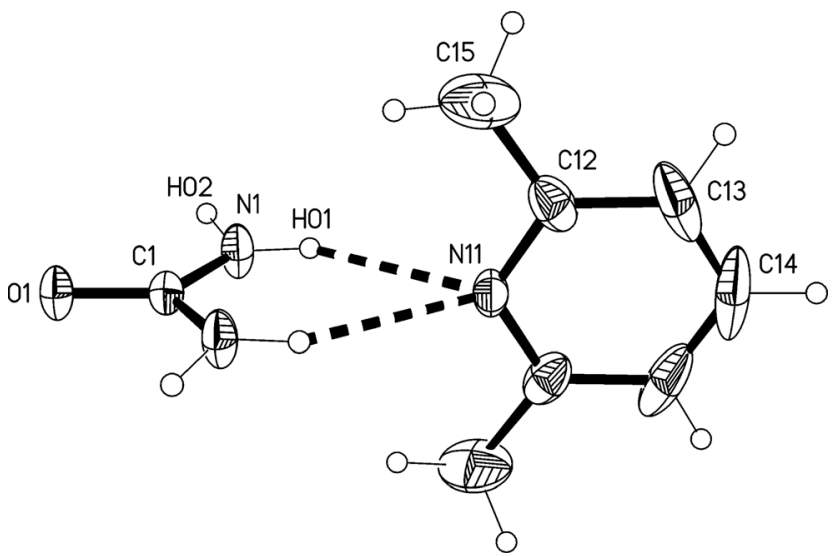

Fig. 1 The formula unit of adduct $1 \mathrm{~m}$ in the crystal. Ellipsoids correspond to $30 \%$ probability levels. Only the asymmetric unit is numbered. The dashed lines correspond to the classical hydrogen bonds within the formula unit.

The molecular packing involves two classical hydrogen bonds, one of which is bifurcated, and one "weak" interaction (Table 2). The two-centre interaction N1-H02 $\cdots \mathrm{O} 1$ links the urea molecules to form a ribbon, consisting of linked $\left[\mathrm{R}_{2}^{2}(8)\right]$ rings, parallel to the $c$ axis (Fig. 2); such ribbons are a well-established feature of urea adducts. ${ }^{2,3,12}$ The bifurcated interaction ( $\mathrm{N} 1-\mathrm{H} 01)_{2} \cdots \mathrm{N} 11$, part of an $\left[\mathrm{R}_{2}^{1}(6)\right]$ ring, connects the lutidine residues peripherally to these ribbons, whereby

Table 2 Details of hydrogen bonding [Å and $\left.{ }^{\circ}\right]$ for adduct $1 \mathrm{~m}^{a}$

\begin{tabular}{llllll}
\hline & $\mathrm{D}-\mathrm{H} \cdots \mathrm{A}$ & $d(\mathrm{D}-\mathrm{H})$ & $d(\mathrm{H} \cdots \mathrm{A})$ & $d(\mathrm{D} \cdots \mathrm{A})$ & $\angle(\mathrm{DHA})$ \\
\hline 1 & $\mathrm{~N} 1-\mathrm{H} 01 \cdots \mathrm{N} 11$ & $0.86(3)$ & $2.37(2)$ & $3.178(3)$ & $155(2)$ \\
2 & $\mathrm{~N} 1-\mathrm{H} 02 \cdots \mathrm{O} 1^{\mathrm{i}}$ & $0.91(2)$ & $2.03(3)$ & $2.940(2)$ & $177(2)$ \\
3 & $\mathrm{C} 14-\mathrm{H} 14 \cdots \mathrm{O} 1^{\mathrm{ii}}$ & 0.95 & 2.51 & $3.460(4)$ & 180
\end{tabular}

${ }^{a}$ Symmetry transformations used to generate equivalent atoms: (i) $-x+1$, $-y,-z+1$; (ii) $x, y+1, z$.

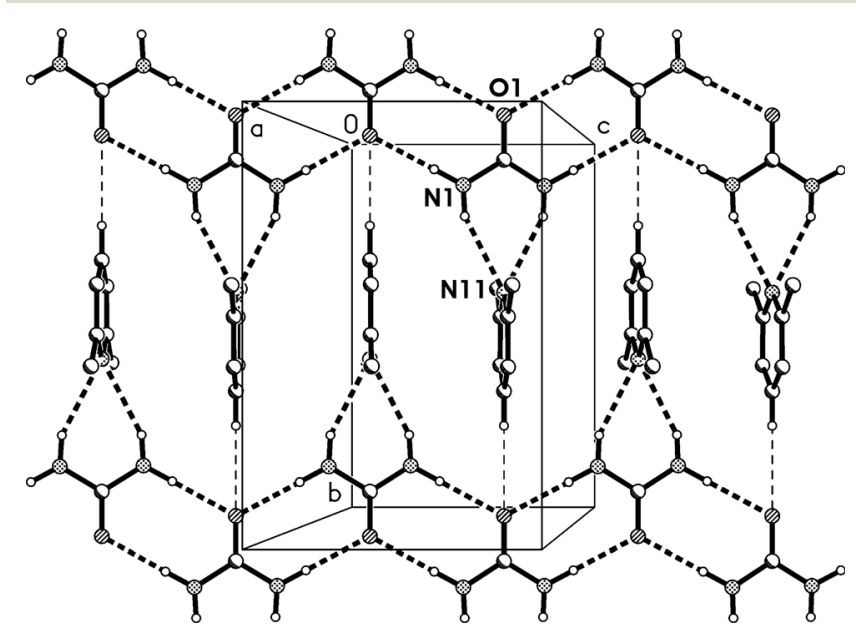

Fig. 2 Packing diagram of adduct $1 \mathrm{~m}$ with view direction perpendicular to the $b c$ plane in the region $x \approx 1 / 2$. Classical hydrogen bonds are drawn as thick and "weak" hydrogen bonds as thin dashed lines. 
the angle $\mathrm{C} 1 \cdots \mathrm{N} 11 \cdots \mathrm{C} 14$ is exactly $180^{\circ}$ by symmetry. The weak interaction $\mathrm{C} 14-\mathrm{H} 14 \cdots \mathrm{O} 1$ links the ribbons to form layers parallel to the $b c$ plane; the acceptor geometry at $\mathrm{O} 1$ is unusual, but this is sometimes observed for urea derivatives, especially where the oxygen is an acceptor of more than two hydrogen bonds, ${ }^{1}$ and even in urea itself. ${ }^{13}$ A view along the $c$ axis (Fig. 3) shows ring stacking, with a vertical distance between rings of $3.71 \AA$ and an offset of $0.9 \AA$.

At this stage it is worth emphasising the two features that, with some modifications, are common to all five structures presented here. The first is the presence of ribbons of linked $\left[R_{2}^{2}(8)\right]$ rings. These are of an extremely simple form in $\mathbf{1 m}$, being built up from just half a urea molecule in the asymmetric unit and being effectively planar (Fig. 2, 3). However, because the oxygens can accept a variable number of classical hydrogen bonds, the ribbons have in principle the ability to interlink; furthermore, they have some degree of torsional freedom and can twist both within a single ring, or along a ribbon (or both), or undergo twisting and/or translation with respect to a neighbouring and/or linked ribbon. The second is the lutidine stacking. A third such feature, relevant only for the 2:1 adducts, is discussed below.

\section{Crystal structure of urea : 2,6 -lutidine $(1: 1)$,} lower temperature form (1t)

The new polymorph 1t, measured at $-173{ }^{\circ} \mathrm{C}$, crystallizes in $P \overline{1}$ with no imposed crystallographic symmetry and $Z=2$; the structure is qualitatively similar to $\mathbf{1 m}$, but the extreme libration is no longer observed. The formula unit is shown in Fig. 4. Corresponding to the loss of crystallographic symmetry, the two residues are now significantly tilted with respect to each other, with $\mathrm{C} 2 \cdots \mathrm{N} 11 \cdots \mathrm{C} 14$ 171.17(3) ${ }^{\circ}$. A similar effect was noted for lithium acetylacetonate, which changes on cooling from orthorhombic to twinned monoclinic and thereby from a linear to a slightly curved chain structure. ${ }^{5 a}$

The molecular packing is also closely similar to that of 1m, but with the following differences: the ribbon direction

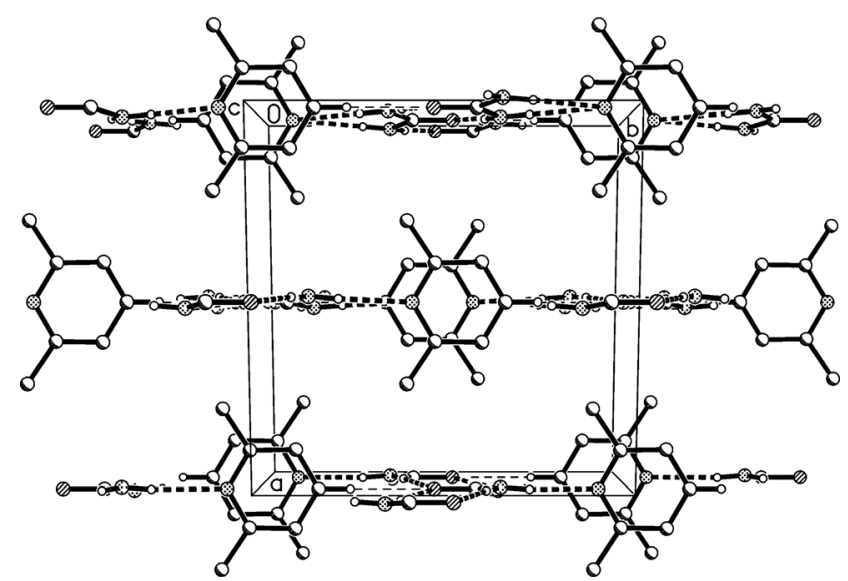

Fig. 3 Packing diagram of adduct $1 \mathrm{~m}$. The view direction is parallel to the $c$ axis. Classical hydrogen bonds are drawn as thick and "weak" hydrogen bonds as thin dashed lines.

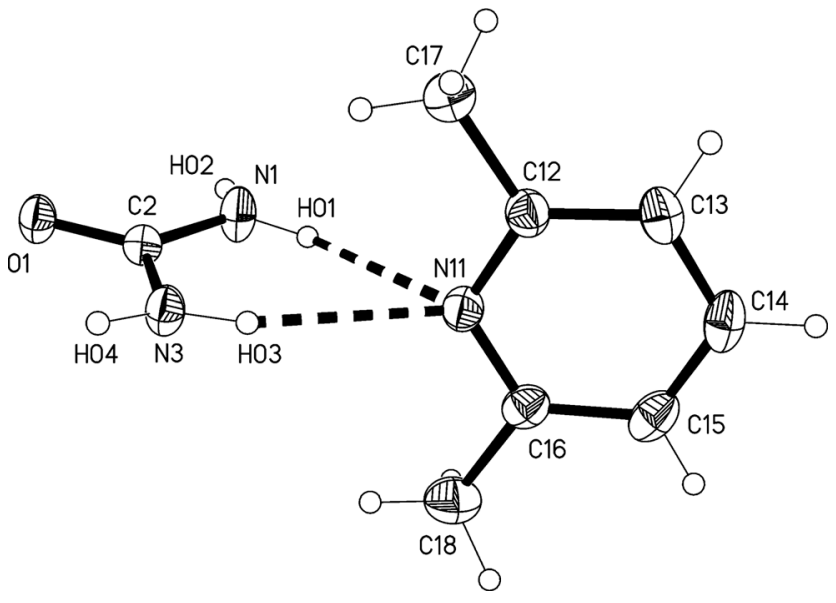

Fig. 4 The formula unit of adduct 1 t in the crystal. Ellipsoids correspond to $50 \%$ probability levels. The dashed lines correspond to the classical hydrogen bonds within the formula unit.

is parallel to the $a$ axis, the layers are parallel to (011), and the tilting is incorporated as a feature of the packing (Table 3, Fig. 5). The lutidine rings stack with a spacing of 3.70 and an offset of $1.0 \AA$ (Fig. 6).

\section{Relationship between the cells of $1 \mathrm{t}$ and $1 \mathrm{~m}$}

The $C$-centred monoclinic cell of $1 \mathbf{m}$ can be converted into a triclinic cell approximately resembling that of $\mathbf{1 t}$ by the appropriate matrix:

$$
\begin{aligned}
& a=11.426 b=11.117 c=7.432 \\
& \alpha=90 \quad \beta=101.24 \gamma=90 \\
& 1 \mathrm{~m} \\
& \downarrow\left(\begin{array}{ccr}
0 & 0 & -1 \\
0.5 & 0.5 & 0 \\
0.5 & -0.5 & 0
\end{array}\right) \\
& a=7.432 b=7.971 \quad c=7.971 \\
& \alpha=88.43 \beta=81.97 \gamma=81.97
\end{aligned}
$$

\begin{tabular}{|c|c|c|c|c|c|}
\hline & $\mathrm{D}-\mathrm{H} \cdots \mathrm{A}$ & $d(\mathrm{D}-\mathrm{H})$ & $d(\mathrm{H} \cdots \mathrm{A})$ & $d(\mathrm{D} \cdots \mathrm{A})$ & $\angle$ (DHA) \\
\hline 1 & N1-H01 $\cdots$ N11 & $0.858(17)$ & $2.351(17)$ & $3.1482(14)$ & $154.9(14)$ \\
\hline 2 & N3-H03 $\cdots$ N11 & $0.896(17)$ & $2.345(17)$ & $3.1743(14)$ & $153.9(13)$ \\
\hline 3 & $\mathrm{~N} 1-\mathrm{H} 02 \cdots \mathrm{O} 1^{\mathrm{i}}$ & $0.905(18)$ & $2.018(18)$ & $2.9225(13)$ & $177.3(14)$ \\
\hline 4 & $\mathrm{~N} 3-\mathrm{H} 04 \cdots \mathrm{O} 1^{\mathrm{ii}}$ & $0.901(17)$ & $2.049(17)$ & $2.9493(13)$ & $177.0(13)$ \\
\hline 5 & $\mathrm{C} 14-\mathrm{H} 14 \cdots \mathrm{O} 1^{\mathrm{iii}}$ & 0.95 & 2.55 & $3.4396(10)$ & 156 \\
\hline
\end{tabular}

and the inverse matrix can be used to convert the 1t cell back, approximately, to $1 \mathrm{~m}$ :

Table 3 Details of hydrogen bonding [Å and $\left.{ }^{\circ}\right]$ for adduct $1 \mathbf{t}^{a}$

${ }^{a}$ Symmetry transformation used to generate equivalent atoms: (i) $-x$, $-y+2,-z$; (ii) $-x+1,-y+2,-z$; (iii) $x, y-1, z+1$. 


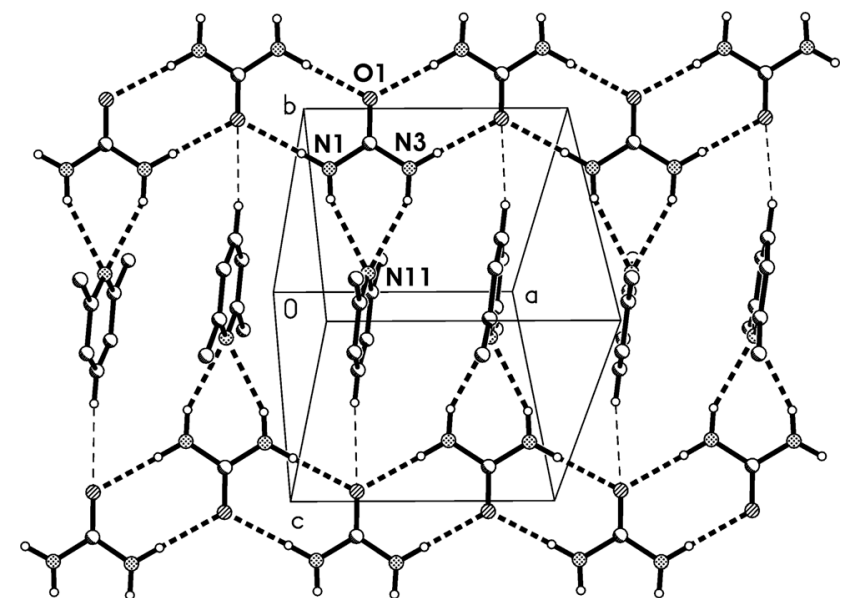

Fig. 5 Packing diagram of adduct 1t with view direction perpendicular to $(011)$ in the region $z \approx 1 / 4$. Classical hydrogen bonds are drawn as thick and "weak" hydrogen bonds as thin dashed lines.

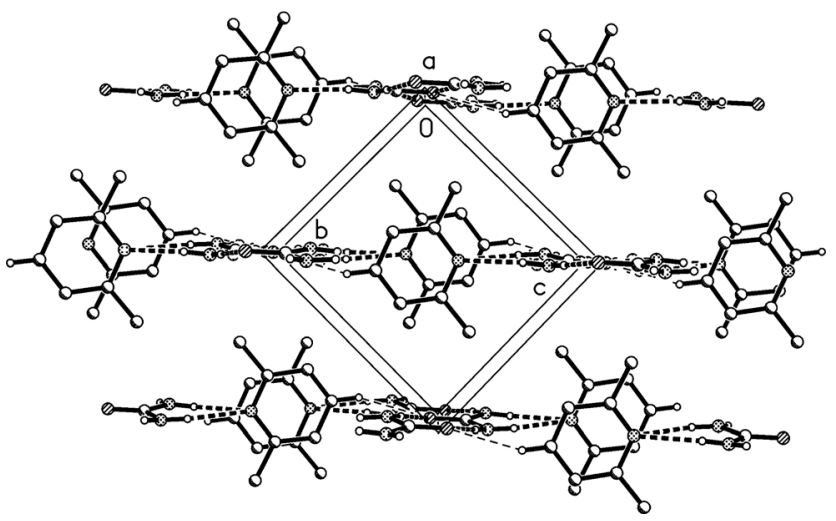

Fig. 6 Packing diagram of adduct 1t with the view direction parallel to the a axis. Classical hydrogen bonds are drawn as thick and "weak" hydrogen bonds as thin dashed lines.

$$
\begin{aligned}
& a=7.413 b=7.672 c=8.173 \\
& \alpha=88.39 \beta=83.56 \gamma=80.06 \\
& \mathbf{1 t} \\
& \downarrow\left(\begin{array}{rrr}
0 & 1 & 1 \\
0 & 1 & -1 \\
-1 & 0 & 0
\end{array}\right) \\
& a=11.366 b=11.051 c=7.413 \\
& \alpha=92.11 \beta=101.37 \gamma=93.62
\end{aligned}
$$

where cell constants are as usual in $\AA$ and degrees.

The relevant directions of both structures are then related in the same way; the urea ribbon direction of $1 \mathrm{~m}$ (its $c$ axis) is physically the same as that of $\mathbf{1 t}$ (its $a$ axis), etc. The twinning may be interpreted as the reduction of libration in $\mathbf{1 m}$ by a tilting of the structure to either side of the monoclinic $b$ axis, which then ceases to be a symmetry axis as the symmetry is lowered; the twinning components of $1 \mathrm{t}$ are related around the direction $\left(b^{*}-c^{*}\right)$, which by the usual matrix methods is shown to be the same as the $b$ axis of $\mathbf{1 m}$. This axis changes from being a crystallographic axis to being a twin axis (the axis about which the twin law acts), which is a common feature of induced twinning. As a further check of the interrelationship, a fragment of the same crystal used to determine the structure of $1 \mathrm{~m}$ was cooled to $100 \mathrm{~K}$, whereupon only the twinned cell $1 \mathrm{t}$ could be found. The crystal did however not survive intact on re-warming, so the reversibility of the twinning was not tested.

The density of $1 \mathrm{t}\left(1.221 \mathrm{~g} \mathrm{~cm}^{-3}\right)$ is greater than that of $1 \mathrm{~m}$ $\left(1.200 \mathrm{~g} \mathrm{~cm}^{-3}\right)$, which might indicate better packing efficiency and higher lattice energy, but the values may not be strictly comparable because of the temperature difference.

\section{Crystal structure of urea : 2,6-lutidine $(2: 1)$}

The $2: 1$ solvate 2 , measured at $-173{ }^{\circ} \mathrm{C}$, crystallizes in Pnma with $Z=4$. The asymmetric unit consists of a lutidine molecule lying in the mirror plane at $z=3 / 4$ and two urea molecules $\# 1$ and $\# 2$ with their $\mathrm{C}=\mathrm{O}$ bonds $(\mathrm{C} 1=\mathrm{O} 1$ and $\mathrm{C} 2=\mathrm{O} 2$ ) lying in the mirror planes at $z=3 / 4$ and $1 / 4$ respectively (see Fig. 7). The bifurcated interaction of urea $\# 1$ to the lutidine is qualitatively the same as observed for the adducts $1 \mathrm{~m}$ and $1 \mathrm{t}$, with an inclination angle $\mathrm{C} 1 \cdots \mathrm{N} 11 \cdots \mathrm{C} 14$ of $170.44(7)^{\circ}$. The two ureas of the asymmetric unit are connected to form an $\left[\mathrm{R}_{2}^{2}(8)\right]$ ring, but subtend an interplanar angle of $20.25(9)^{\circ}$.

The residues pack to form corrugated layers of urea molecules parallel to the $a b$ plane, perpendicular to which the lutidines are attached via urea molecules that project from the layers (Fig. 8a, Table 4). The urea layers contain two standard motifs: first, ribbons of $\left[\mathrm{R}_{2}^{2}(8)\right]$ rings parallel to the $b$ axis and secondly, chains of rings, graph set $\mathrm{C}(4)\left[\mathrm{R}_{2}^{1}(6)\right]$, that lie parallel to the $a$ axis and link the ribbons. The chains involve only the second urea molecule, whereby $\mathrm{O} 2$ accepts four hydrogen bonds (two in the chain and two in the ribbon). Such chains of rings represent a robust supramolecular synthon in the structure of urea itself ${ }^{13}$ and of many $N, N^{\prime}$-substituted ureas. ${ }^{14}$ As far as we are aware, such a two-dimensional urea substructure has not been observed before in any urea solvate.

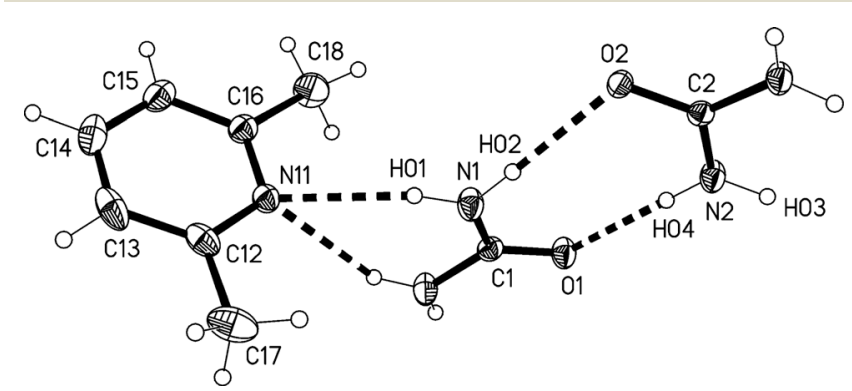

Fig. 7 The formula unit of adduct 2 in the crystal. Ellipsoids correspond to $50 \%$ probability levels. Only the asymmetric unit is numbered. The dashed lines correspond to the classical hydrogen bonds within the formula unit. 

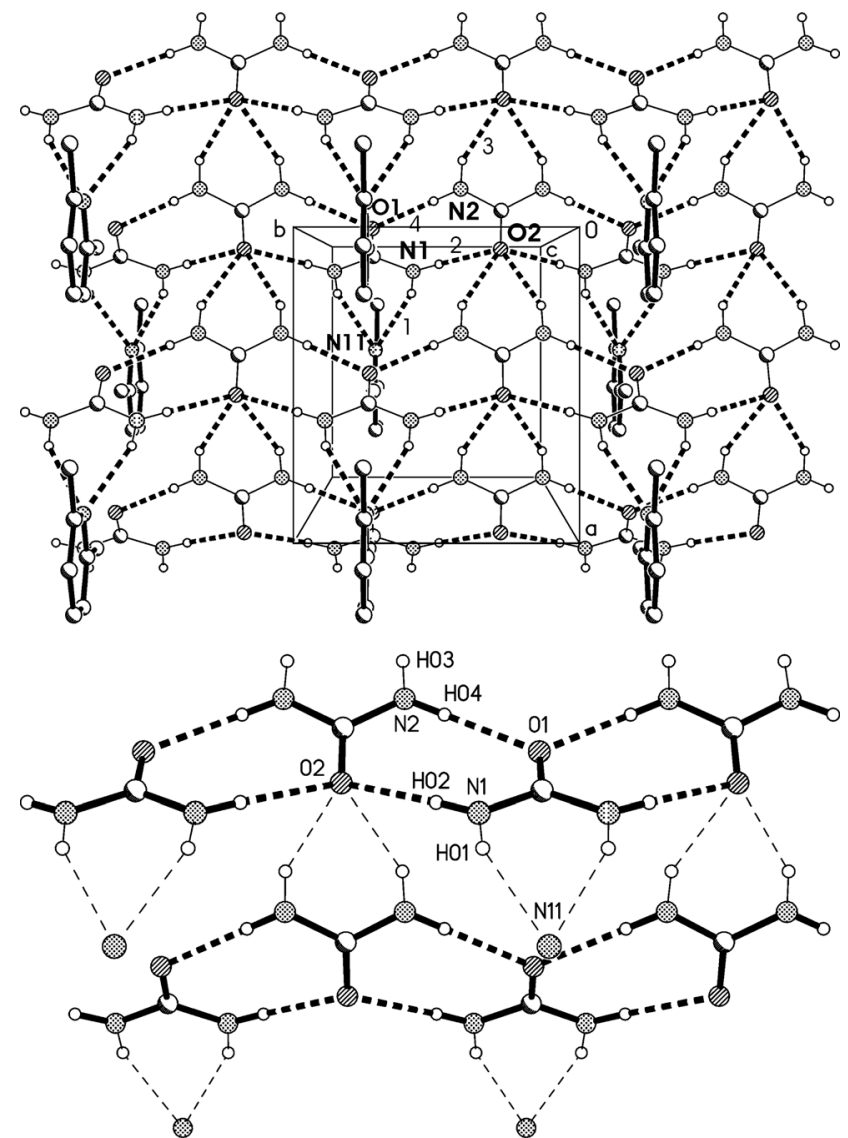

Fig. 8 (a), Above: packing diagram of 2 with view direction parallel to the $c$ axis in the region $z \approx 1 / 4$; the mirror planes run vertically at $y=1 / 4$ and $3 / 4$. Hydrogen bonds are drawn as thick dashed lines and numbered according to Table 4 . The urea ribbons run horizontally (e.g. at the top of the diagram) and the chains of rings vertically (e.g. immediately to the left of the cell). (b), Below: simplified version (see text).

Fig. 9 presents a view of the packing parallel to the $b$ axis, and shows the corrugated nature of the urea layers with the projecting urea molecules. The lutidine rings stack with a vertical spacing of 3.65 and an offset of $1.0 \AA$.

The urea layers represent a common feature of the $2: 1$ adducts 2 and 3 but, although broadly similar in form, nonetheless display some significant differences. In 2 the ribbons are of a very simple form, with mirror planes passing through each carbonyl group; the ribbons are linked by "extra" hydrogen bonds to the quadruple acceptor $\mathrm{O} 2$, whereby the linked ribbons show little or no mutual horizontal displacement (Fig. 8b). The simplicity of this structure means that it can be

Table 4 Details of hydrogen bonding [Å and $\left.{ }^{\circ}\right]$ for adduct $2^{a}$

\begin{tabular}{llllll}
\hline & $\mathrm{D}-\mathrm{H} \cdots \mathrm{A}$ & $d(\mathrm{D}-\mathrm{H})$ & $d(\mathrm{H} \cdots \mathrm{A})$ & $d(\mathrm{D} \cdots \mathrm{A})$ & $\angle(\mathrm{DHA})$ \\
\hline 1 & $\mathrm{~N} 1-\mathrm{H} 01 \cdots \mathrm{N} 11$ & $0.869(15)$ & $2.318(16)$ & $3.1248(15)$ & $154.4(13)$ \\
2 & $\mathrm{~N} 1-\mathrm{H} 02 \cdots \mathrm{O} 2$ & $0.871(16)$ & $2.102(16)$ & $2.9698(11)$ & $174.2(13)$ \\
3 & $\mathrm{~N} 2-\mathrm{H} 03 \cdots \mathrm{O} 2$ & $0.878(15)$ & $2.192(16)$ & $2.9963(13)$ & $152.1(14)$ \\
4 & $\mathrm{~N} 2-\mathrm{H} 04 \cdots \mathrm{O} 1$ & $0.870(15)$ & $2.018(16)$ & $2.8879(11)$ & $179.5(13)$
\end{tabular}

${ }^{a}$ Symmetry transformations used to generate equivalent atoms: (i) $x-1 / 2, y,-z+1 / 2$.

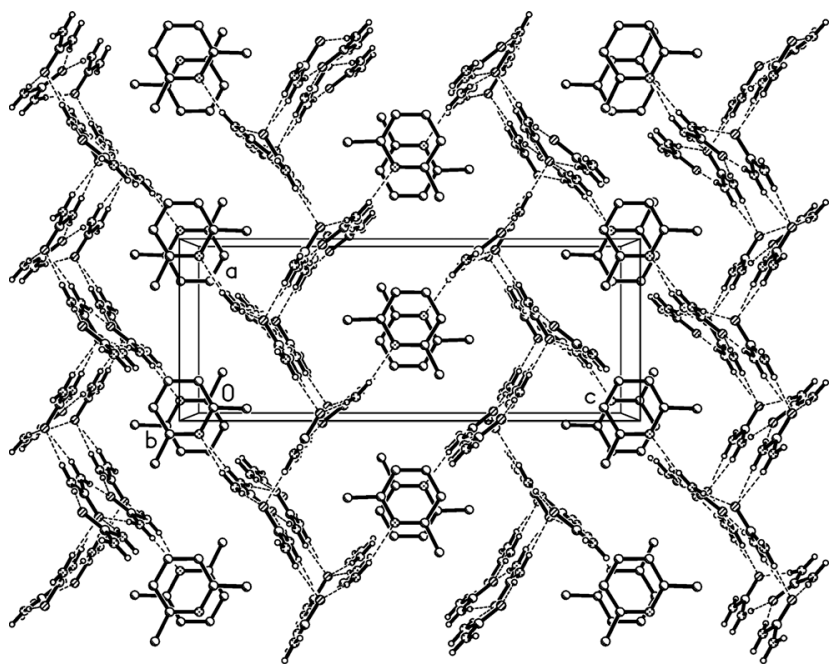

Fig. 9 Packing diagram of 2 with view direction parallel to the $b$ axis. Hydrogen bonds are drawn as thin dashed lines.

regarded as a standard for two-dimensional urea layers; the standard undergoes considerable modification in the structures of 3 (see below).

Crystal structure of urea : 3,5-lutidine (2:1), higher temperature form (3o)

The higher temperature form 30 of the solvate 3 , measured at $-100{ }^{\circ} \mathrm{C}$, crystallizes in the non-centrosymmetric orthorhombic space group $A b m 2$ (ref. 15 ) with $Z=8$. The asymmetric unit was chosen to form a complete unit with as many hydrogen bonds as possible; the two independent lutidine molecules then lie in the mirror plane at $z=3 / 4$ and the four independent urea molecules lie with their $\mathrm{C}=\mathrm{O}$ bonds in the mirror planes at $z=1 / 4$ (molecules \#2 \& \#3) and $3 / 4$ (molecules \#1 \& \#4) (Fig. 10). Again, the bifurcated interactions

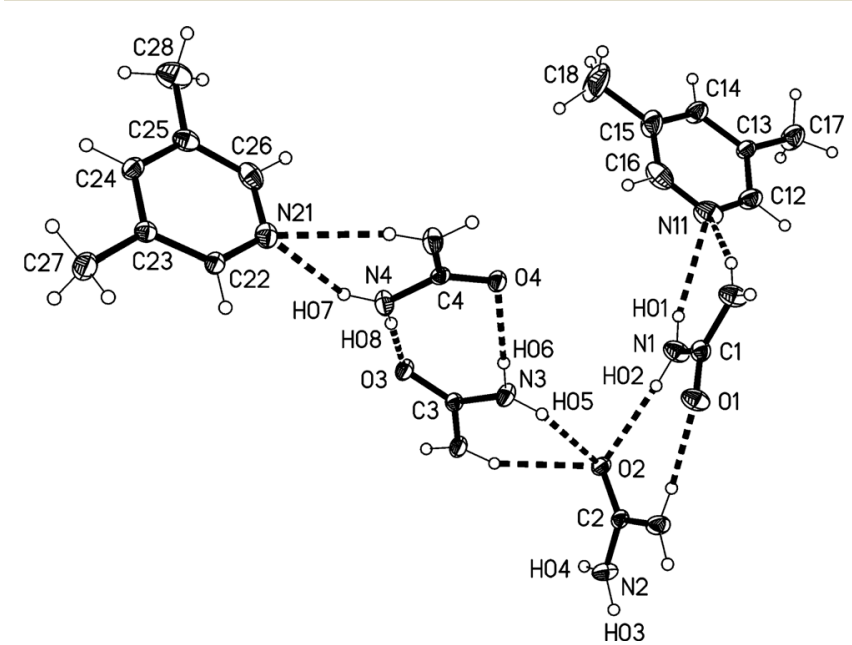

Fig. 10 The double formula unit of adduct 30 in the crystal. Ellipsoids correspond to $30 \%$ probability levels. Only the asymmetric unit is numbered. The dashed lines correspond to classical hydrogen bonds. 
of urea to lutidine are qualitatively the same as observed above, with inclination angles $\mathrm{C} 1 \cdots \mathrm{N} 11 \cdots \mathrm{C} 14 \quad 170.9(2)$ and $\mathrm{C} 4 \cdots \mathrm{N} 21 \cdots \mathrm{C} 24162.7(2)^{\circ}$. The urea pairs that form the $\left[\mathrm{R}_{2}^{2}(8)\right]$ rings subtend interplanar angles of 29.0(2) (ureas \#1 \& \#2) and 35.0(2) $)^{\circ}$ (ureas \#3 \& \#4).

The residues pack in a way reminiscent of adduct 2 to form corrugated layers of urea molecules parallel to the $b c$ plane (Fig. 11a, Table 5). There are two crystallographically distinct types of ribbons of $\left[R_{2}^{2}(8)\right]$ urea rings, one based on ureas $\# 1$ and $\# 2$, the other on ureas $\# 3$ and $\# 4$; they both run parallel to the $b$ axis. Although a cursory inspection of the
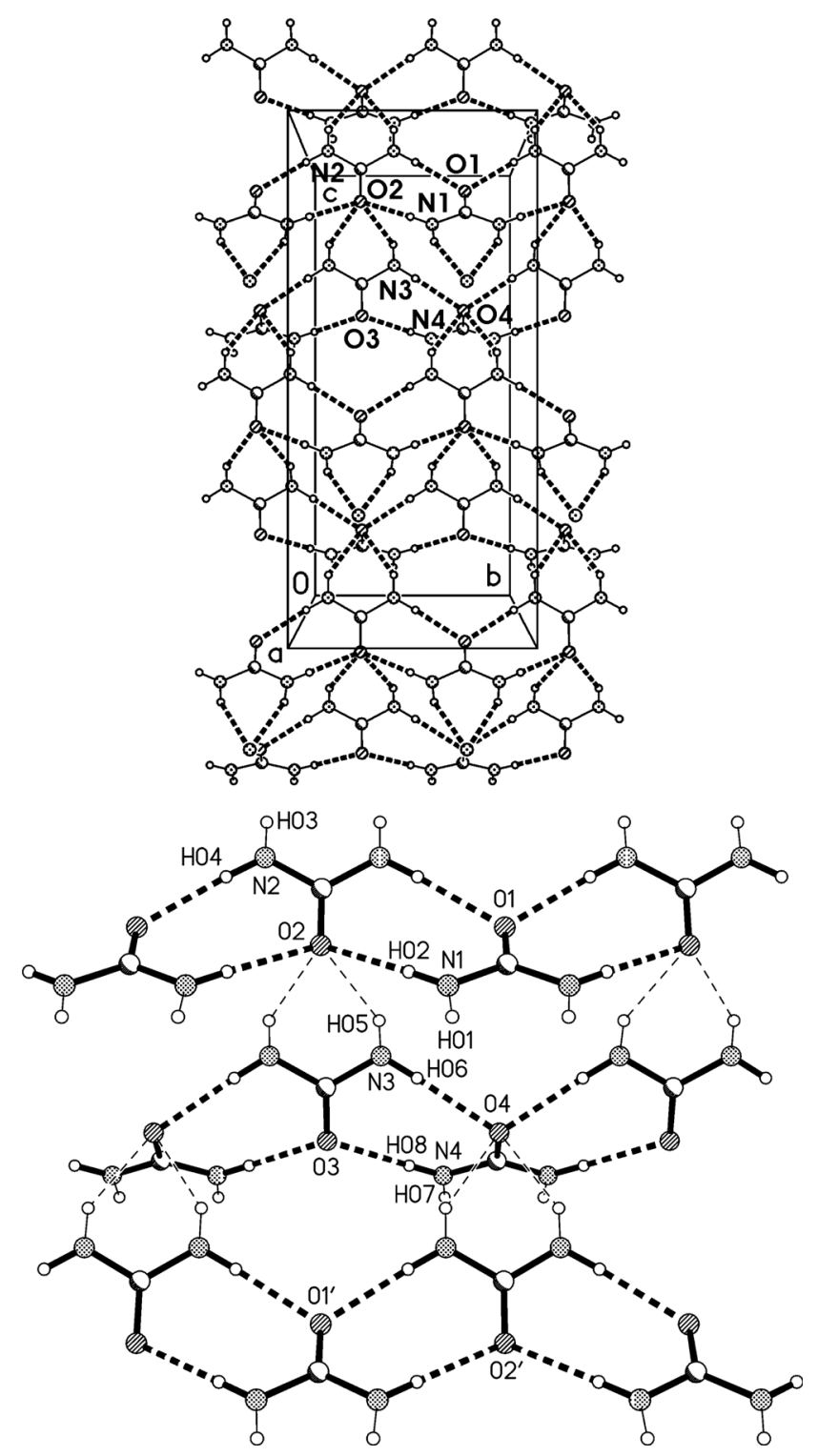

Fig. 11 (a), Above: packing diagram of 30 with view direction parallel to the $a$ axis in the region $x \approx 1 / 4$; the mirror planes run vertically at $y=1 / 4$ and $3 / 4$. Hydrogen bonds are drawn as thick dashed lines. The urea ribbons run horizontally. Lutidines are represented only by the nitrogen atom N11 (the second lutidine lies behind this plane). (b), Below: simplified version without lutidines (see text). Primes indicate symmetry-equivalent atoms.
Table 5 Details of hydrogen bonding [Å and $\left.{ }^{\circ}\right]$ for adduct $30^{a}$

\begin{tabular}{|c|c|c|c|c|c|}
\hline & $\mathrm{D}-\mathrm{H} \cdots \mathrm{A}$ & $d(\mathrm{D}-\mathrm{H})$ & $d(\mathrm{H} \cdots \mathrm{A})$ & $d(\mathrm{D} \cdots \mathrm{A})$ & $\angle(\mathrm{DHA})$ \\
\hline & $\mathrm{N} 1-\mathrm{H} 01 \cdots \mathrm{N} 11$ & $0.878(16)$ & $2.33(2)$ & $3.161(4)$ & $157(3)$ \\
\hline & $\mathrm{N} 1-\mathrm{H} 02 \cdots \mathrm{O} 2$ & $0.873(16)$ & $2.119(16)$ & $2.988(3)$ & $174(2)$ \\
\hline 3 & $\mathrm{~N} 2-\mathrm{H} 03 \cdots \mathrm{O} 4^{\mathrm{i}}$ & $0.876(17)$ & $2.29(2)$ & $3.072(3)$ & $148(3)$ \\
\hline 4 & $\mathrm{~N} 2-\mathrm{H} 04 \cdots \mathrm{O} 1^{\mathrm{ii}}$ & $0.891(16)$ & $2.043(17)$ & $2.932(3)$ & $175(3)$ \\
\hline 5 & N3-H05 $\cdots \mathrm{O} 2$ & 0.86 & $2.28(2)$ & 3.072 & 151(3) \\
\hline & 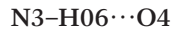 & & $2.080(17)$ & $2.964(3)$ & $177(3)$ \\
\hline & $\mathrm{N} 4-\mathrm{H} 07 \cdots \mathrm{N} 21$ & $0.884(16)$ & $2.32(2)$ & $3.136(4)$ & $154(3)$ \\
\hline & N4-H08 $\cdots \mathrm{O} 3$ & $0.880(17)$ & $2.034(17)$ & $2.914(3)$ & $178(3)$ \\
\hline
\end{tabular}

${ }^{a}$ Symmetry transformations used to generate equivalent atoms: (i) $x$, $y-1 / 2, z+1 / 2$; (ii) $x, y-1, z$.

packing diagrams (especially Fig. 12) might suggest a packing closely analogous to that of 2 , there are some important differences (Fig. 11b). First, the quadruple hydrogen bond acceptors $\mathrm{O} 2$ and $\mathrm{O} 4$ behave in a subtly different manner; although both accept two hydrogen bonds from the ribbon below them, $\mathrm{O} 4$ is formally on the "wrong" side of the $\left[\mathrm{R}_{2}^{2}(8)\right]$ ring to do this (it is enabled to do so by the mutual tilting of the two ribbons involved). Secondly, there is a discontinuity after every second ribbon, whereby the following ribbons are shifted sideways by one ring; thus the urea $\left[\mathrm{R}_{2}^{1}(6)\right]$ rings do not form a continuous chain as in adduct 2 . Formally this is associated with the $A$-centring (compare the positions of the three pairs of urea $\left[R_{2}^{1}(6)\right]$ rings at bottom left, centre right, top left).

Fig. 12 presents a view of the packing parallel to the $b$ axis, and again shows the corrugated nature of the urea layers with their projecting urea molecules. The lutidine rings stack with a vertical spacing of 3.605 and an offset of $0.5 \AA$ (stacks of ring 1) or $0.9 \AA$ (stacks of ring 2).

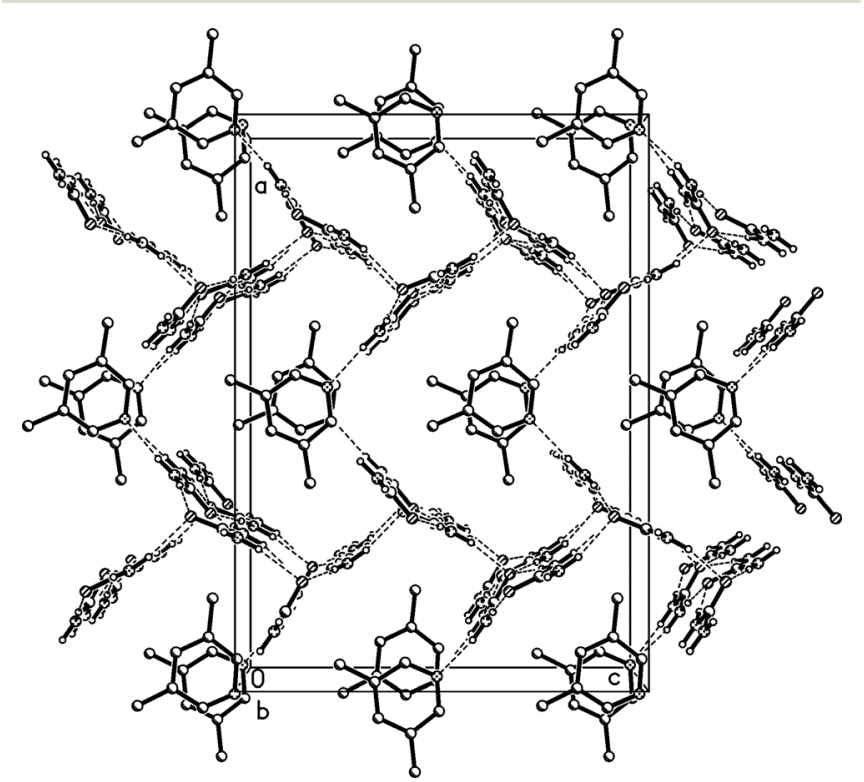

Fig. 12 Packing diagram of 30 with view direction parallel to the $b$ axis. Hydrogen bonds are drawn as thin dashed lines. Lutidine molecules \#1 stack at $x \approx 1 / 2$ and \#2 at $x \approx 0,1$. 
Crystal structure of urea : 3,5-lutidine (2:1), lower temperature form $(3 \mathrm{~m})$

The lower temperature form $3 \mathrm{~m}$ of the solvate 3 , measured at $-173{ }^{\circ} \mathrm{C}$, crystallizes in the non-centrosymmetric monoclinic space group $C c$, which has no special positions, with $Z=4$. The asymmetric unit consists of one lutidine and two urea molecules (Fig. 13). The inclination angle $\mathrm{C} 1 \cdots \mathrm{N} 11 \cdots \mathrm{C} 14$ is $169.2(1)^{\circ}$ and the angle between the urea planes is $34.0(2)^{\circ}$.

The residues again pack to form corrugated layers of urea molecules, now parallel to the $a c$ plane, perpendicular to which the lutidines are attached (Fig. 14, Table 6). The ribbons of $\left[\mathrm{R}_{2}^{2}(8)\right]$ urea rings run parallel to the $c$ axis. In the previous two structures, the oxygen of the urea(s) coordinating to lutidine accepts two hydrogen bonds and the oxygen of the other urea(s) accepts four. In $3 \mathrm{~m}$ all the urea oxygens accept three hydrogen bonds, and this entails another reorientation of the ribbons (Fig. 14b), which no longer lie approximately above and below each other (vertically in the two-dimensional representations given here) but are laterally staggered corresponding to the direction of the monoclinic $c$ axis. The displacement should be equal to half the distance between the mirror planes or $\frac{1}{4} b_{30}$, some $1.8 \AA$.

Fig. 15 presents a view of the packing parallel to the $c$ axis; the lutidine rings stack with a vertical spacing of 3.61 and an offset of $0.7 \AA$, although successive rings are not exactly parallel (interplanar angle $2^{\circ}$ ).

\section{Relationship between the cells of $3 \mathrm{~m}$ and 30}

The orthorhombic cell of 30 can be converted into a monoclinic cell resembling that of $\mathbf{3 m}$ by the appropriate matrix:

$$
\begin{aligned}
& a=21.737 b=7.210 c=15.590 \\
& \alpha=90 \quad \beta=90 \quad \gamma=90 \\
& 30 \\
& \downarrow\left(\begin{array}{ccc}
0 & -0.5 & 0.5 \\
1 & 0 & 0 \\
0 & 1 & 0
\end{array}\right) \\
& a=8.588 b=21.737 c=7.210 \\
& \alpha=90 \quad \beta=114.82 \gamma=90
\end{aligned}
$$

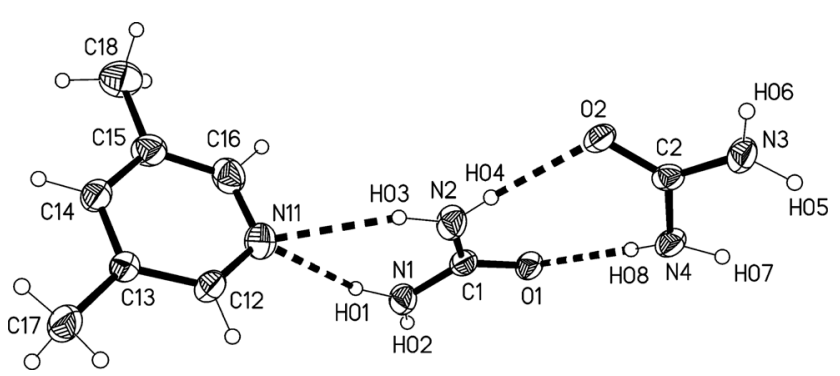

Fig. 13 The formula unit of adduct $3 \mathrm{~m}$ in the crystal. Ellipsoids correspond to $50 \%$ probability levels. The dashed lines correspond to classical hydrogen bonds.
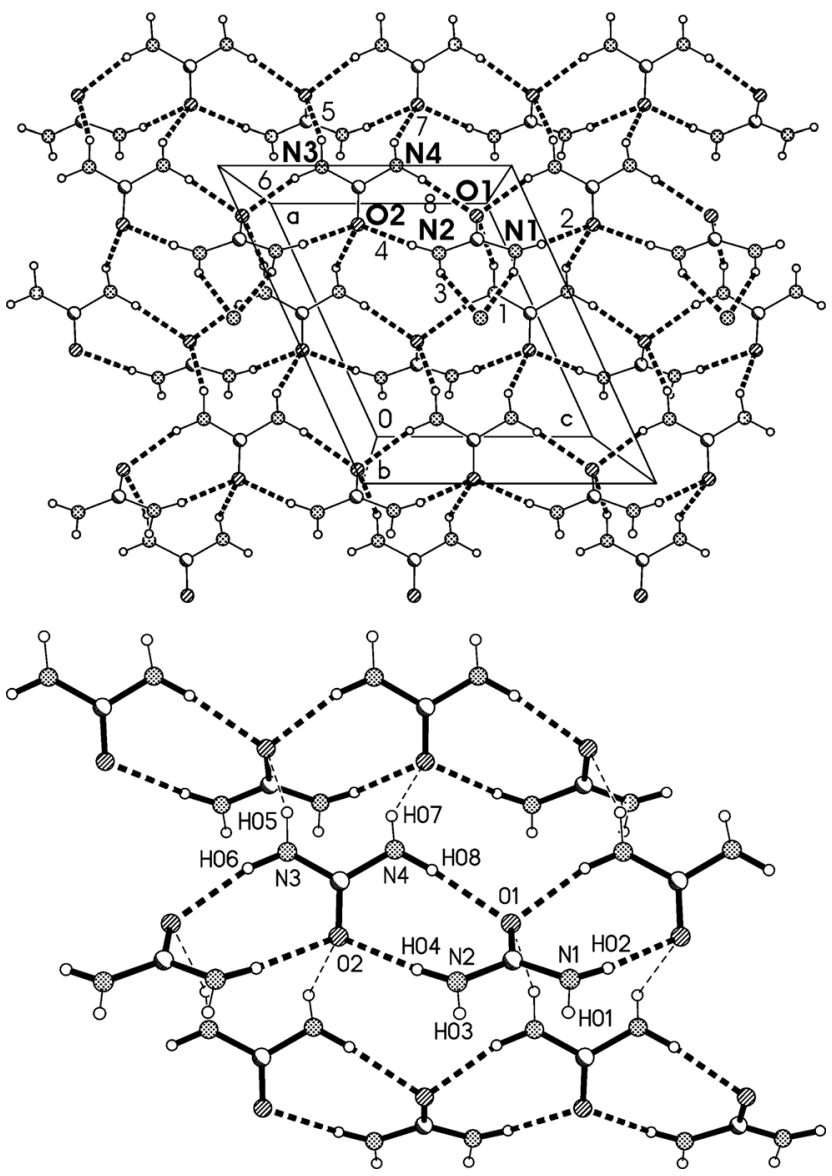

Fig. 14 (a), Above: packing diagram of $3 \mathrm{~m}$ with view direction parallel to the $b$ axis in the region $y \approx 1 / 4$. Hydrogen bonds are drawn as thick dashed lines and numbered according to Table 6 . For clarity, only three lutidine nitrogens are shown (e.g. the acceptor of $\mathrm{H}$ bonds \#1 and \#3). The urea ribbons run horizontally. The $a^{*}$ axis (see text) runs vertically. (b), Below: simplified version without lutidines (see text).

The new cell should however be primitive rather than centred (the expected appropriate subgroup of Abm2 would be $P c$, not $C c$ ). ${ }^{16 a}$ The "additional" $C$-centring in $3 \mathrm{~m}$ renders e.g. all the lutidines and their stacks equivalent, in contrast to the lutidine stacks in 30 , which consist of two sets corresponding to the two independent molecules. Calculation suggests that the coordinates of the two independent lutidine

Table 6 Details of hydrogen bonding [Å and $\left.{ }^{\circ}\right]$ for adduct $3 \mathrm{~m}^{a}$

\begin{tabular}{llllll}
\hline & $\mathrm{D}-\mathrm{H} \cdots \mathrm{A}$ & $d(\mathrm{D}-\mathrm{H})$ & $d(\mathrm{H} \cdots \mathrm{A})$ & $d(\mathrm{D} \cdots \mathrm{A})$ & $\angle(\mathrm{DHA})$ \\
\hline 1 & $\mathrm{~N} 1-\mathrm{H} 01 \cdots \mathrm{N} 11$ & $0.90(2)$ & $2.26(3)$ & $3.113(4)$ & $158(4)$ \\
2 & $\mathrm{~N} 1-\mathrm{H} 02 \cdots \mathrm{O} 2^{\mathrm{i}}$ & $0.89(2)$ & $2.06(2)$ & $2.939(4)$ & $168(4)$ \\
3 & $\mathrm{~N} 2-\mathrm{H} 03 \cdots \mathrm{N} 11$ & $0.91(2)$ & $2.32(3)$ & $3.165(4)$ & $153(4)$ \\
4 & $\mathrm{~N} 2-\mathrm{H} 04 \cdots \mathrm{O} 2$ & $0.90(2)$ & $2.07(3)$ & $2.948(4)$ & $168(4)$ \\
5 & $\mathrm{~N} 3-\mathrm{H} 05 \cdots \mathrm{O} 1^{\text {ii }}$ & $0.92(2)$ & $2.16(3)$ & $3.021(3)$ & $154(4)$ \\
6 & $\mathrm{~N} 3-\mathrm{H} 06 \cdots \mathrm{O} 1^{\text {iii }}$ & $0.92(2)$ & $2.03(3)$ & $2.926(4)$ & $167(4)$ \\
7 & $\mathrm{~N} 4-\mathrm{H} 07 \cdots \mathrm{O} 2^{\text {iv }}$ & $0.91(2)$ & $2.22(3)$ & $3.050(3)$ & $152(4)$ \\
8 & $\mathrm{~N} 4-\mathrm{H} 08 \cdots \mathrm{O} 1$ & $0.91(2)$ & $2.06(2)$ & $2.951(4)$ & $166(4)$
\end{tabular}

${ }^{a}$ Symmetry transformations used to generate equivalent atoms: (i) $x$, $y, z+1$; (ii) $x+1 / 2,-y+1 / 2, z-1 / 2$; (iii) $x, y, z-1$; (iv) $x+1 / 2,-y+$ $1 / 2, z+1 / 2$. 


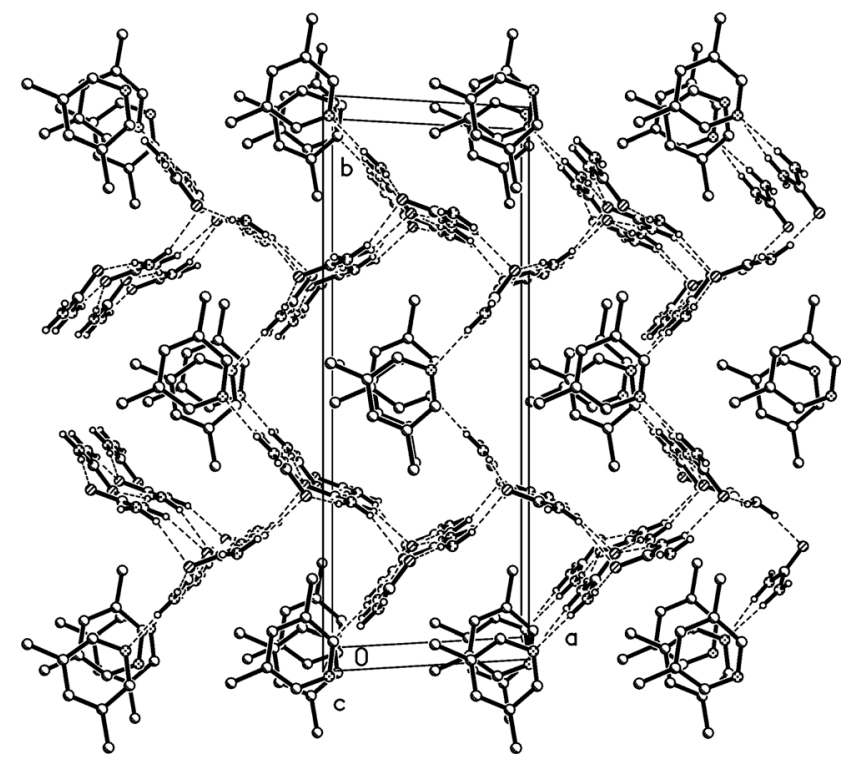

Fig. 15 Packing diagram of $3 \mathrm{~m}$ with view direction parallel to the $c$ axis. Hydrogen bonds are drawn as thin dashed lines. All lutidine molecules are equivalent (cf. Fig. 12).

molecules of $3 \mathbf{0}$, transformed to $3 \mathrm{~m}$, are reasonably consistent with the $C$-centring in their $x$ and $y$ coordinates, but the $z$ coordinates differ by approximately $0.23 c_{3 \mathrm{~m}}$. However, the urea ribbons and their accompanying lutidines are mutually displaced with respect to the 30 structure by a translation of $\frac{1}{4} b_{30}$, and this is the same axis. We thus conclude that the $C$-centring arises as a new symmetry operation between the previously independent formula units, induced by the "slippage" of the urea ribbons with their accompanying lutidines. ${ }^{16 b}$

The inverse matrix can be used to convert the $3 \mathrm{~m}$ cell back, approximately, to 30 :

$$
\begin{aligned}
a & =8.583 \quad b=21.484 \quad c=7.205 \\
\alpha & =90 \quad \beta=114.41 \quad \gamma=90 \\
\mathbf{3 m} & \\
\downarrow & \left(\begin{array}{lll}
0 & 1 & 0 \\
0 & 0 & 1 \\
2 & 0 & 1
\end{array}\right) \\
a & =21.484 \quad b=7.205 \quad c=15.632 \\
\alpha & =89.59 \quad \beta=90 \quad \gamma=90
\end{aligned}
$$

The twinning of $3 \mathrm{~m}$ by $180^{\circ}$ rotation about $\boldsymbol{a}^{*}$ (previously the orthorhombic $c$ axis direction, vertical in Fig. 14a) can be interpreted in terms of the lateral slippage between the urea ribbons in 30 taking place either to the left or to the right.

As for adducts 1 , the density of $3 \mathrm{~m}\left(1.248 \mathrm{~g} \mathrm{~cm}^{-3}\right)$ is greater than that of $30\left(1.236 \mathrm{~g} \mathrm{~cm}^{-3}\right)$, but again this may be partially attributable to the temperature difference.

\section{Conclusions}

Reasonable explanations in terms of molecular displacements can be given for the twinning effects that are induced by cooling the adducts urea : 2,6-lutidine (1:1) and urea : 3,5-lutidine $(2: 1)$.

\section{Acknowledgements}

We are grateful to Dr. Regine Herbst-Irmer, University of Göttingen, for helpful discussions on twinning phenomena and in particular for advice on the use of new SHELXL versions in cases of reticular twinning.

\section{Notes and references}

1 C. Taouss, L. Thomas and P. G. Jones, CrystEngComm, 2013, 15, 6829-6836.

2 J. D. Lee and S. C. Wallwork, Acta Crystallogr., 1965, 19, 311-313.

3 J. Ashurov, B. Ibragimov and S. Talipov, Acta Crystallogr., Sect. E: Struct. Rep. Online, 2012, 68, 0504.

4 Twin categories and twin laws have been formalised by M. Nespolo and G. Ferraris, Acta Crystallogr., Sect. A: Found. Crystallogr., 2004, 60, 89-95, who also discuss previous classifications, and by H. D. Flack, Acta Crystallogr., Sect. A: Found. Crystallogr., 1987, 43, 564-568. For general descriptions of the refinement of twinned structures see R. Herbst-Irmer and G. M. Sheldrick, Acta Crystallogr., Sect. B: Struct. Sci., 1998, 54, 443-449 and R. Herbst-Irmer and G. M. Sheldrick, Acta Crystallogr., Sect. B: Struct. Sci., 2002, 58, 477-481; the latter gives notice of the improvements later to be implemented in SHELXL-2012.

5 e.g. (a) C. A. Austin, B. D. Leskiw and M. Zeller, Phase Transitions, 2009, 82, 211-220; (b) E. J. Chan, A. D. Rae and T. R. Welberry, Acta Crystallogr., Sect. B: Struct. Sci., 2009, 65, 509-515. Twinning may of course also be associated with order/disorder phenomena rather than simple molecular displacements, e.g. J. W. Bats, P. Schell and J. W. Engels, Acta Crystallogr., Sect. E: Struct. Rep. Online, 2013, 69, 01028. Temperature change can also lead to single-crystal to single-crystal transitions; for a recent example in a triazole complex of $\mathrm{ZnBr}_{2}$, see $\mathrm{X}$. $\mathrm{X}$. Wu, Y. Y. Wang, P. Yang, Y. Y. Xu, J. Z. Huo, B. Ding, Y. Wang and X. G. Wang, Cryst. Growth Des., 2014, 14, 477-490. Finally, cooling can lead to drastic mechanical stress and crystal destruction, as is often seen on shock-cooling of crystals for low temperature diffractometer measurements. Note added on revision: A referee has commented (paraphrased by us) "The observed twinning is a secondary effect that does not necessarily have to occur. Probably not all the crystals of the daughter phases are twinned". We are happy to concur with the former comment. The latter may or may not be true in the cases described here; we looked at many (around 15) crystals of 1t in the hope of finding an untwinned crystal, but all were twinned. We only succeeded in cooling one crystal of 30 to $100 \mathrm{~K}$, forming a twin of $3 \mathrm{~m}$.

6 Oxford Diffraction, CrysAlis PRO, Oxford Diffraction Ltd., Yarnton, England, 2013. 
7 (a) G. M. Sheldrick, Acta Crystallogr., Sect. A: Found. Crystallogr., 2008, 64, 112-122; (b) G. M. Sheldrick, SHELXL-2012, a Program for refining Crystal Structures, University of Göttingen, Germany, 2012.

8 Siemens XP, version 5.03, Siemens Analytical X-Ray Instruments, Madison, Wisconsin, U.S.A, 1994.

9 For two-component twins, the diffractometer control program (here ref. 6) uses two orientation matrices for the data reduction and outputs the intensity data with reflections flagged as pure component 1 or 2 (the latter reflections may be omitted in some cases) or overlapped $1 / 2$. The refinement program (here ref. 7) recognises this data format and refines a scale factor for the relative twin volumes. This is known in shorthand as the "HKLF5 method", because "HKLF 5" is the command for reading the modified data format, but it has never been formally published, to the best of our knowledge.

10 Or "reticular merohedry" if the overlap is exact; this is discussed for rhombohedral systems by R. Herbst-Irmer, in Crystal Structure Refinement, a Crystallographer's Guide to SHELXL, ed. P. Müller, IUCr/OUP, 2006, ch. 7.

11 S. Parsons, H. D. Flack and T. Wagner, Acta Crystallogr., Sect. B: Struct. Sci., Cryst. Eng. Mater., 2013, 69, 249-259.

12 P. Fernandes, A. J. Florence, F. Fabbiani, W. I. F. David and K. Shankland, Acta Crystallogr., Sect. E: Struct. Rep. Online, 2012, 68, 0355.

13 For an interpretable packing diagram of urea, see S. Swaminathan, B. M. Craven and R. K. McMullan, Acta Crystallogr., Sect. B: Struct. Sci., 1984, 40, 300-306.

14 R. Custelcean, Chem. Commun., 2008, 295-307 (review article).

15 The more modern name for this space group (no. 39) is Aem2: International Tables for X-Ray Crystallography, ed. T. Hahn, IUCr/Springer, 5th edn, 2005, vol. A.

16 (a) U. Müller, Symmetriebeziehungen zwischen verwandtenKristallstrukturen, Vieweg + Teubner, 2012; (b) We are grateful to Prof. Müller for helpful discussions and in particular for the comment that the residues at $x_{30} \approx 1 / 2$ shift by $c a . \pm \frac{1}{4} b_{30}$ with respect to those at $x_{3 \mathrm{o}} \approx 0$ or 1 . 